\title{
PAULO FREIRE E A PEDAGOGIA CRÍTICA: SEU LEGADO PARA UMA NOVA PEDAGOGIA DO SUL
}

\author{
PAULO FREIRE Y LA PEDAGOGÍA CRÍTICA: SU LEGADO PARA UNA \\ NUEVA PEDAGOGÍA DESDE EL SUR
}

\author{
PAULO FREIRE AND CRITICAL PEDAGOGY: HIS LEGACY FOR A NEW \\ PEDAGOGY OF THE SOUTH
}

José Rubens Lima JARDILINO ${ }^{1}$

Diana Elvira SOTO ARANGO ${ }^{2}$

\begin{abstract}
RESUMO: O artigo trata da relevância do pensamento e da ação de Paulo Freire e das respostas que ele recebeu nos últimos cinquenta anos. Além disso, propõe-se demonstrar a relevância e o legado de Freire para a educação no mundo, especialmente para a América Latina. Para continuar nos caminhos que nos propomos, primeiro refletiremos sobre o contexto da escrita de Freire - Educação e atualdade brasileira - contra os golpes políticos no Brasil (antigos e atuais). Em seguida, trazer a memória o legado de Paulo Freire na condição de um clássico latino-americano, seguido dos contextos em que seu pensamento e obra foram concebidos, expressando sua singularidade e, talvez, sua universalidade. Por fim, far-se-á uma análise das teses que discordam da referida universalidade do pensamento de Freire, partindo de alguns conceitos/categorias de sua obra. Finaliza-se com o desafio de releitura de Freire na construção de um pensamento pedagógico do sul alimentada pelo debate das epistemologias do sul.
\end{abstract}

PALAVRAS-CHAVE: Pensamento pedagógico. Pedagogia crítica. Pensamento freireano.

RESUMEN: El artículo tratará de la relevancia del pensamiento y acción de Paulo Freire y las contestaciones que ha sufrido a lo largo de los últimos cincuenta años. Además, se propone demostrar la relevancia y el legado de Freire para la educación en el mundo, especialmente, para América Latina. Para seguir en las sendas que nos proponemos, primero lo haremos una reflexión sobre el contexto de la escritura de Freire - Educación y actualidad brasilera - frente a los golpes políticos en Brasil (antiguo y actual). Después traer a la

\footnotetext{
${ }^{1}$ Universidad Federal de Ouro Preto (UFOP), Mariana - MG - Brasil. Docente Pesquisador. Doutor em Sociologia com pós-doutorado em Ciências da Educação na Universidade de Laval, Canadá; Universidade Pedagógica e Tecnológica da Colômbia (UPTC) e em História na Universidade Pablo de Olavide, Espanha. Diretor do Grupo de Pesquisa: História de la Universidad Latinoamericana (HISULA/UPTC) y Formción y Profesión Docente (FOPROFI/UFOP/Cnpq). ORCID: http://orcid.org/0000-0003-2394-9465. E-mail: jrjardilino@gmail.com

${ }_{2}^{2}$ Universidad Pedagógica y Tecnológica de Colombia (UPTC), Tunja - Boyacá - Colômbia. Diretora do Doutorado em Ciências da Educação (RUDECOLOMBIA/UPTC). Pesquisadora Senior-Emérita de Colciencias. Diretora de Grupos de Pesquisa: HISULA y ILAC (Categoría A COLCIENCIAS). Diretora-Fundadora da Revista RHELA (Indexada B). Fundadora e Presidenta Emérita da Sociedad de Historia de la Educación Latinoameicana (SHELA). Doutora em Filosofia e Ciências da Educação, com Pós-doutorado no Conselho Superior de Pesquisas Científicas na Espanha-CSIC. ORCID: https://orcid.org/0000-0002-3821-7550. E-mail: dianaelvirasoto@gmail.com
} 
memoria el legado de Paulo Freire en la condición de un clásico latinoamericano, seguido de los contextos en los cuales su pensamiento y obra se gestaron, expresando su singularidad y, quizas, su universalidad. Finalmente se hace un análisis de las tesis que contestan la dicha universalidad del pensamiento de Freire, bajo algunos conceptos/categorias de su obra. Se finaliza con el desafío de una nueva lectura de Freire en la construcción de un pensamiento pedagógico desde el sur y alimentado por el debate de las epistemologías del sur.

PALABRAS CLAVE: Pensamiento pedagógico. Pedagogia crítica. Pensamiento freireano.

ABSTRACT: The article will discuss the relevance of Paulo Freire's thought and action as well as the criticism of his thinking over the last fifty years. In addition, it is proposed to demonstrate the relevance and legacy of Freire for education in the world, especially for Latin America. To continue in the ways we propose, we will first reflect on the context of Freire's writing - Education and brazilian reality - against the political blows in Brazil (old and current). Then bring to memory the legacy of Paulo Freire as a Latin American classic, followed by the contexts in which his thought and work were conceived, expressing his uniqueness and perhaps his universality. Finally, an analysis will be made of the theses that disagree with the aforementioned universality of Freire's thinking, starting from some concepts / categories of his work. It ends with the challenge of Freire's re-reading in the construction of a pedagogical thought of the South nourished by the debate of the epistemologies of the south.

KEYWORDS: Pedagogical thought. Critical pedagogy. Freirean thought.

\section{Introdução}

Quando este artigo estava sendo escrito, sob um cenário e contexto político se vivia no Brasil, tomamos como lição o que Paulo Freire escreveu em Educação e atualidade brasileira (1959) - um texto para o concurso de ingresso na universidade - no qual expressou que a posição do 'homem' no mundo não é apenas passiva. $\mathrm{O}$ tema do compromisso com sua realidade está à frente dos demais. Porém, as possibilidades de intervenção estão imbricadas em uma realidade histórica determinada. Por isso, Freire entendia que somente a formação e o desenvolvimento de uma consciência crítica são imperativos para a construção do compromisso do homem com a realidade. É muito provável que este escrito esteja contaminado pelo contexto em que estamos inseridos no Brasil.

O artigo irá tratar da relevância do pensamento e da ação de Paulo Freire, bem como das contestações que tem sofrido ao longo dos últimos cinquenta anos. Para mais, se propõe também demonstrar a relevância e o legado de Freire para a educação no mundo, especialmente, para América Latina. Para seguir nos caminhos que nos propomos, primeiro, realizaremos a reflexão sobre o contexto da escrita de Freire - Educação e atualidade 
brasileira - frente aos golpes políticos no Brasil (antigo e atual). Depois, relembremos o legado de Paulo Freire na condição de um clássico latino americano, seguido dos contextos nos quais seu pensamento e obra se geriram, expressando sua singularidade e, porventura, sua universalidade. Finalmente, se conclui com as teses que respondem à universalidade do pensamento de Freire, sob alguns conceitos/categorias de sua obra.

Realizamos a introdução deste texto com três citações importantes. Na primeira, utilizamos as próprias palavras de Paulo sobre sua estadia em um país/irmão, sua segunda pátria, que demonstra sua pela adaptação à sociedade chilena e sua gratidão pelo que Chile representou em sua trajetória intelectual. Em Pedagogia da esperança: um reencontro com a pedagogia do oprimido, Paulo escreveu com nostalgia deste tempo.

\begin{abstract}
Em casa, em Santiago - não foram raras as vezes em que, de tal forma envolvido pelo trabalho, gratificado por ele, eu me surpreendia com o pequeno sol iluminando o pequeno quarto que transformara em biblioteca, na rua Alcides de Gasperi, 500, Apoquito, Santiago. Com o sol e com os pássaros, com a manhã, com o novo dia. Olhava então pela janela o pequeno jardim que Elza fizera, as roseiras que ela plantara. Não sei se a casa estará lá ainda, pintada de azul como era à época. Não poderia re-pensar a Pedagogia do oprimido sem pensar, sem lembrar alguns dos lugares onde a escrevi, mas sobretudo, um deles, a casa onde vivi tempo feliz, e de onde parti do Chile, carregando saudades, sofrido por partir, mas esperançoso para responder os desafios que esperavam por mim. (1992, p. 61-62).
\end{abstract}

Os quatro anos e meio que vivi no Chile foram assim anos de um profundo aprendizado. Era a primeira vez, com exceção da rápida passagem pela Bolívia, que eu vivia a experiência de "tomar distância" geograficamente, com consequências epistemológicas, no Brasil. [...] No fundo, eu buscava reentender as tramas, os fatos, os feitos em que me envolvera. A realidade chilena me ajudava, na sua diferença com a nossa, a compreender melhor as minhas experiências e estas, revistas, me ajudavam a compreender o que ocorria e poderia ocorrer no Chile. (1992, p. 43-44).

As duas seguintes citações se referem a dois importantes intelectuais "schoolar" da Pedagogia Crítica que falam a respeito do que Freire representa para o pensamento Crítico Educacional. São eles, Henry Giroux e Michael Apple, que em recentes artigos publicados concedem a Freire um lugar especial na teoria educacional no mundo. Começamos com as citações para o estabelecimento de nossa tese de que a obra de Freire deveria ficar nas estantes das bibliotecas destinadas à Filosofia e não apenas no lugar da prática, didática e pedagogia, conforme designado pelos pedagogos. Vejamos o que dizem Giroux ${ }^{3}$

${ }^{3}$ Henry Giroux nasceu em Providence, Estados Unidos, em 18 de setembro de 1943. Ensinou história em uma escola secundária em Barrington, Rhode Island, de 1968 a 1975. Depois de obter seu doutorado na Universidade Carnegie Mellon em 1977, tornou-se professor de educação na Universidade de Boston entre 1977 e 1983. Em 1983, tornou-se professor de educação e renomado estudioso da Universidade de Miami em Oxford, Ohio, onde 
Numa época em que a memória está sendo apagada e a relevância política da educação é afastada pela adoção da linguagem da medição e quantificação, é ainda mais importante lembrar o legado e a obra de Paulo Freire. Desde os anos 1980, existiram poucos intelectuais, se é que existiu algum, no cenário educacional norte-americano, que alcançasse tal rigor teórico, coragem cívica e o sentido de responsabilidade moral de Paulo Freire. Seu exemplo é mais importante do que nunca: com as instituições públicas de educação básica e superior, cada vez mais, sob o cerco de uma série de forças neoliberais e conservadoras, é imperativo que os educadores se apropriem do entendimento de Freire sobre empoderamento e do potencial democrático da educação. A linguagem da educação crítica, da esperança são seu legado, que está cada vez mais ausente de muitos discursos liberais e conservadores sobre os problemas educacionais atuais e as vias de resolução das reformas. Paulo passou a vida direcionada pela crença de que valia a pena lutar pelos elementos radicais da democracia, de que a educação crítica é um elemento fundamental para a mudança social progressiva, e de que a forma em que pensamos em política é inseparável da forma como compreendemos o mundo, o poder e a vida moral a que aspiramos. Paulo acreditava firmemente que a democracia não poderia perdurar sem a cultura formativa que a possibilita. No momento presente em que as instituições públicas de educação básica e superior estão sendo associadas à lógica de mercado, e sua conformidade a este modelo econômico, à perda de poder, conhecer as contribuições significativas da obra e legado de Paulo freire é ainda mais importante" (2016, p. 297). ${ }^{4}$

também atuou como diretor do Centro de Estudos Culturais e Educacionais (Centro de Educação e Estudos Culturais). Mudou-se para a Pennsylvania State University, onde assumiu o cargo de professor de Waterbury de 1992 a maio de 2004. Também atuou como diretor do Fórum de Waterbury em Estudos Culturais e de Educação. Mudou-se para a Universidade McMaster em maio de 2004, onde atualmente ministra a cadeira de Cadeias globais de televisão na área de Ciências da Comunicação. Em maio de 2005, a Universidade Memorial do Canadá concedeu-lhe um doutorado honorário em Letras. É um crítico cultural americano e um dos teóricos fundadores da pedagogia crítica naquele país. Conhecido por seu trabalho pioneiro em pedagogia pública, estudos culturais, estudos de jovens, ensino superior, estudos de mídia e teoria crítica.

${ }^{4}$ En un momento en que la memoria está siendo borrada y la relevancia política de la educación es alejada por el abrazo del lenguaje de la medición y de la cuantificación, es aún más importante recordar el legado y la obra de Paulo Freire. Desde los años 1980, ha habido pocos intelectuales, si es que hubo alguno, en la escena norteamericana educativa, que alcanzaron el rigor teórico, el coraje cívico y el sentido de responsabilidad moral de Paulo Freire. Su ejemplo es más importante ahora que nunca: con las instituciones públicas de educación básica y superior, cada vez más, bajo el cerco de una serie de fuerzas neoliberales y conservadoras, es imperativo que los educadores se apropien del entendimiento de Freire sobre empoderamiento y del potencial democrático de la educación. El lenguaje de la educación crítica, de la esperanza son su legado, que está cada vez más ausente de muchos discursos liberales y conservadores sobre los problemas educativos actuales y las vías de hacer las reformas. Paulo pasó la vida dirijida por la creencia de que valía la pena luchar por los elementos radicales de la democracia, de que la educación crítica es un elemento fundamental para el cambio social progresivo, y de que la forma en que pensamos en política es inseparable de aquella como comprendemos el mundo, el poder y la vida moral a la que aspiramos. Paulo creía firmemente que la democracia no puede durar sin la cultura formativa que la hace posible. En el momento presente en que las instituciones públicas de educación básica y superior están siendo asociadas a la lógica del mercado, y su conformidad a ese modelo económico, a la pérdida de poder, conocer las contribuciones significativas de la obra y el legado de Paulo Freire es ahora, más importante" (2016, p. 297) 
A segunda citação é de Michael Apple ${ }^{5}$, fala de seus colóquios com Freire sobre a arquitetura teórica como um lugar significativo para a atuação prática. Anuncia que Freire jamais pensou dicotomicamente na teoria e na prática. Passemos a escutá-lo:

Paulo Freire e eu, em muitas conversas, passávamos horas discutindo a importância, não só de intervenções teóricas, mas também da importância crucial da práxis, de intervir nas vidas diárias de realidades culturais e pedagógicas e de deixar que estas intervenções contestem (respondam) ao trabalho político e teórico que se busca desenvolver. Infelizmente, muitos "teóricos críticos" da educação tem se esquecido da necessidade de tal ação. A teoria "domina", com rara exceção, proveniente das realidades institucionais e de comunidades reais, em lutas reais. As lutas afrobrasileiras contra a subjugação não eram abstrações para Freire. Ele as via como parte das lutas necessárias contra a dominação. Neste artigo, ainda que Freire não esteja presente, quero seguir o diálogo com ele sobre a questão racial. Minha base epistemológica será decididamente freireana. Quero questionar a "cultura do silêncio" em que vivemos, de modo que possa ser transformada. Aqueles de nós que estão comprometidos com políticas e práticas educacionais emancipadoras e antirracistas, seriam perspicazes ao dirigir sua crítica não só aos efeitos raciais sobre os mercados e padrões culturais, mas também para as "formas criativas" utilizadas por movimentos neoliberais e neoconservadores para convencer as massas de que estas políticas são simplesmente tecnologias neutras que nos ajudarão a fazer uma educação mais eficiente e eficaz (APPLE, 2016, p. 279). ${ }^{6}$

Não devemos cometer anacronismo na história, mas devemos examiná-la para ouvir o que os eventos do passado, embora recentes, querem nos dizer. O motivo que levou a Paulo Freire para o exílio no Chile é o "beckground" (pano de fundo) do cenário político-econômico do Brasil no início da década de 1960 e que já se estendia nos governos de natureza populista desde a década de 1930, quando o país começava a sofrer forte pressão do capitalismo

${ }^{5}$ Michael W. Apple nasceu em 1942. Doutor em Humanidades pela Universidade McGill Montreal, Quebec, Canadá. É professor da disciplina de Currículo, Instrução e Estudos de Políticas de Educação na Universidade de Wisconsin, Madison. Recebeu títulos de Doutor Honoris Causa e professor Ilustre na Universidade de Manchester, Londres, Califórnia, Rosário e universidades na China. Trabalhou como professor da Escola primária e secundária em Nova Jersey, atuou como diretor do Sindicato dos Professores. Apple trabalhou com sistemas de ensino estatais, universidades e ativistas no mundo, com a finalidade de democratizar a pesquisa, a política e a prática educativa.

6 Paulo Freire y yo, en muchos diálogos, quedábamos horas discutiendo la importancia, no sólo de intervenciones teóricas, sino también de la importancia crucial de la praxis, de intervenir en las vidas diarias de realidades culturales y pedagógicas y de dejar que estas intervenciones contesten (respondan) al trabajo político y teórico que se busca desarrollar. Desafortunadamente, muchos "teóricos críticos" de la educación se han olvidado de la necesidad de tal acción. La teoría "domina", con rara excepción, proveniente de las realidades institucionales y de comunidades reales, en luchas reales. Las luchas de afro-brasileños contra la subyugación no eran abstracciones para Freire. Él las veía como parte de las luchas necesarias contra la dominación. En este artículo, aunque Freire ya no esté presente, quiero continuar el diálogo con él sobre la cuestión racial. Mi base epistemológica será decididamente freireana. Quiero interrogar la "cultura del silencio" en que vivimos, de modo que pueda transformarse. Aquellos de nosotros que están comprometidos con políticas y prácticas educativas emancipatorias y antirracistas, serían perspicaces al dirigir su crítica no sólo a los efectos raciales sobre los mercados y estándares culturales, sino también para las "formas creativas" utilizadas por movimientos neoliberales y neo- conservadores para convencer a las masas de que estas políticas son simplemente tecnologías neutras que nos ayudarán a hacer la educación más eficiente y eficaz (APPLE, 2016, p. 279). 
internacional para adotar uma política econômica de expansão industrial. Adotar uma política social que desse conta de manter e com a expectativa futura de ampliar esse modelo econômico o mais rápido possível, era condição imperativa para que o Brasil avançasse em sua economia. No entanto, "Esta política de massas foi sendo tolerada até que sua radicalização, que começou a criar obstáculos mais diretos ao controle, pelo capital internacional, do desenvolvimento da economia brasileira". Este foi o verdadeiro motivo da derrubada do Governo Goulart em 1964, pelo empresariado nacional associado ao capital internacional (a elite do dinheiro), que se valeu dos militares e das classes médias da sociedade, motivados pela pregação anticomunista dos Mass Media. Nesse sentido, qualquer semelhança com a época em que vivemos no Brasil é mera ficção da realidade.

Vejamos a frase de um manifestante em 2015 no Brasil: “Chega de doutrinação marxista. Basta de Paulo Freire". Esta é uma frase que esteve em um cartaz em uma manifestação contra o governo de Dilma Rousseff em Brasília, capital do Brasil, em março de 2015. Causou muita polêmica nas redes sociais, inclusive provocou uma resposta da ONU em suas redes sociais com as frases/citações de Paulo Freire: “A educação não transforma o mundo. A educação muda as pessoas e as pessoas transformam o mundo" (facebook/março/2015); "Quando a educação não é libertadora, o sonho do oprimido é ser opressor" (Twitter, março de 2015). Sai então, a ONU em defesa do educador brasileiro, internacionalmente conhecido na pedagogia crítica.

\section{Por que devemos relembrar o legado de Paulo Freire?}

Uma resposta breve seria, primeiro, porque é um clássico latino-americano, não só da pedagogia, mas do pensamento das humanidades do continente. Segundo, porque tem um pensamento vigoroso e atualizado para a reflexão em nossos projetos de formação do homem latino-americano. Sua concepção de homem se nutre a partir da realidade da nossa América. Continuamos com um breve olhar biográfico e matrizes de seu pensamento políticopedagógico.

Paulo Reglus Neves Freire nasceu em 19 de setembro de 1921 em Recife, Pernambuco, uma das regiões mais pobres do país, onde cedo pôde experimentar as dificuldades de sobrevivência das classes populares. Trabalhou inicialmente no SESI (Serviço Social da Indústria) e no Serviço de Extensão Cultural da Universidade de Recife. Sua filosofia educacional se expressou primeiro em 1958 em sua tese do concurso para a Universidade de Recife e, posteriormente, como professor de História e Filosofia da Educação 
da Universidade, bem como em suas primeiras experiências de alfabetização, como a do nordeste (Angico - Rio Grande do Norte), em 1963. Paulo Freire faleceu em 2 maio de 1997 em São Paulo.

Paulo Freire é autor de muitas obras, dentre as quais se destaca: Educação como Prática de Liberdade (1967), Pedagogia do Oprimido (1968), Ação Cultural para a Liberdade (1975) ${ }^{7}$. Foi reconhecido mundialmente por sua práxis educativa por meio de inúmeras homenagens, além de ter seu nome adotado por muitas instituições. É cidadão honorário de várias cidades no Brasil e no exterior. Paulo Freire recebeu o título de doutor honoris causa por vinte e sete universidades. Por seus trabalhos na área da educação, recebeu, entre outros, os seguintes prêmios: "Prêmio Rei Balduíno para o Desenvolvimento" (Bélgica, 1980); "Prêmio UNESCO de Educação para a Paz" (1986) e "Prêmio Andrés Bello", da Organização dos Estados Americanos, como Educador do Continente (1992). Em 10 de abril de 1997, lançou seu último livro, intitulado Pedagogia da Autonomia: saberes necessários para a prática educativa.

No Brasil não se aplica nem sequer seu método de alfabetização. Há experiências de êxito pontuais, mas não se utiliza sua filosofia e proposta política-pedagógica para a orientação dos programas da política educativa. Mais adiante, veremos sua obra sob o ponto de vista de seus críticos a seu legado no Brasil.

A pregação anticomunista do passado a que nos referimos anteriormente fazia parte de um pacote de ações orientadas pela nova ideologia educacional que atacou violentamente a base cultural brasileira e a substituiu por uma concepção instrumentalista de educação, que foi organizada intencionalmente em função do crescimento econômico. O Estado autoritário e intervencionista se organizou de modo a incrementar diferentes mecanismos de repressão que alcançaram, entre outros, aos que estavam envolvidos com uma postura educacional que vinculava qualquer orientação ideológica diferente da população trabalhadora. Justamente neste cenário, Paulo Freire desenvolvia uma experiência inovadora no contexto educacional brasileiro. Esta experiência nasceu no Movimento de Cultura Popular - MCP, criado em

${ }^{7}$ Além destas obras apontadas acima, o autor tem uma vasta obra, entre outros, destacamos os escritos africanos: Cartas a Guiné Bissau (1980), A importância do ato de ler e o processo de libertação (1982a), os livros em diálogo com outros intelectuais: com Sérgio Guimarães - Sobre a Educação; e Aprendendo com a própria história; com Sérgio Guimarães e Moacir Gadotti - Pedagogia: diálogo e conflito; com Antonio Faúndez. Por uma pedagogia da pergunta; com Frei Betto. Uma escola chamada Vida; com Ira Shor, Medo e Ousadia: a cotidianidade do docente que se arrisca a praticas uma pedagogia transformadora. Os últimos trabalhos publicados: Educação na cidade, traz reflexões de seus desafios em cargos administrativos à frente da Secretaria Municipal da Educação em São Paulo, no primeiro governo do Partido dos Trabalhadores e com a primeira prefeita da cidade - Luiza Erundina (1989-92) Pedagogia da Esperança e Política e Educação, e antes de sua morte publicou, encerrando sua série de Pedagogias, o livro Pedagogia da Autonomia, como um resumo de suas pedagogias. 
Recife - PE, no início dos anos 1960, era um movimento de intelectuais e de artistas e, dentro do MCP, Paulo Freire passou a coordenar os projetos chamados Círculos de Cultura e Centros de Cultura.

Estes projetos que se somam a outros oriundos do Movimento de Educação de BaseMEB, são objetos principais da ação repressora do novo regime ditatorial, pois representavam a ideologia de esquerda preocupada com a formação cultural da classe trabalhadora e era combatida a qualquer preço sob a justificativa de constituir um ensino subversivo.

Sua concepção de educação e, logicamente, sua proposta educacional que mostrou um resultado altamente positivo na experiência em Angicos - RN consistia em afirmar que todo ato educacional é um ato político, pelo fato da educação carregar a potencialidade da transformação da sociedade por intermédio de uma consciência crítica da realidade, tarefa que tanto o educador quanto o educando devem assumir em um ato educativo.

Com estes pressupostos de educação, passou a ser conhecido como educador popular progressista e sua proposta educativa chegou ao conhecimento de instâncias do governo Federal que, por meio do convite do Ministro da Educação Paulo de Tarso Santos que, assim que assumiu o ministério, convocou Paulo Freire para elaborar um projeto nacional de alfabetização. Assim, nascia o Programa Nacional de Alfabetização que tinha Paulo Freire como coordenador de um projeto auspiciado, pois desejava uma alfabetização politizadora para cerca de 5 milhões de adultos.

Esta educação politizadora, também chamada de problematizadora, proposta por Paulo Freire, não podia ser vinculada à nova ideologia que o Estado intervencionista havia adotado para manter a hegemonia político-econômica. Assim, em 14 de abril, duas semanas depois do golpe de Estado que derrubou ao presidente João Goulart, o programa foi extinto e, em 16 de julho de 1964, dia do aniversário de sua primeira esposa Elza Maia Costa de Oliveira (falecida em 1986), Paulo Freire foi preso. Seu exílio iniciou na Bolívia, onde permaneceu por pouco tempo até ir para o Chile. Paulo Freire foi professor convidado em Harvard em 1969, 10 anos diretor de Educação para os países do chamado terceiro mundo.

Por que Freire é o patrono da educação? É simples. Na área acadêmica da educação, da pedagogia, ninguém possui o reconhecimento internacional que ele tem. $\mathrm{O}$ critério da avaliação entre pares é fundamental para a ciência; portanto, se seus livros foram traduzidos para mais de 40 idiomas, se as principais universidades do mundo lhe deram prêmios e se seu trabalho inspira práticas educacionais, é um sinal de que é importante para o seu campo do saber. 
Freire é considerado patrono da educação no Brasil desde 2012, foi homenageado dando nome a institutos acadêmicos em países europeus como Finlândia, Inglaterra, Espanha e em outros continentes, América (Estados Unidos) e África do Sul. Mas em sua terra natal, tem sido criticado por manifestantes por conta de sua "influência esquerdista" no ensino.

Paulo Freire é o terceiro pensador mais citado do mundo na área das ciências humanas. O levantamento foi feito através do Google Scholar por Elliot Green, professor da London School of Economics. Freire é citado 72.359 vezes, ficando atrás apenas do filósofo americano Thomas Kuhn (81.311) e do sociólogo Everett Rogers (72.780). É mais referenciado que pensadores como Michel Foucault (60.700) e Karl Marx (40.237).

Outro ponto de reconhecimento de sua obra foi a menção da "Pedagogia do Oprimido" entre os 100 livros mais solicitados em universidades de língua inglesa no mundo, segundo o projeto Open Syllabus. O livro de Freire foi o único brasileiro a entrar no top 100 da lista de mais de um milhão de estudos universitários americanos, ingleses, australianos e neozelandeses.

\section{América Latina, berço da universalidade de Freire}

Assim que chegou ao Chile, Paulo Freire se envolveu com um trabalho que o colocava em frente a muitas lutas pela educação popular, mas neste momento estas lutas seriam trabalhadas em outro território. Sobre seu primeiro trabalho em solo chileno o relata assim:

Se bem me lembro, chegamos a Arica em uma sexta-feira, e no segundo dia Santiago de Mello e Strauss me levaram ao gabinete de Jacques Chonchol, do Instituto de Desenvolvimento Agropecuário. Apesar de minha dificuldade em entender o espanhol de Jacques, tivemos uma conversa muito cordial, e saí de seu gabinete contratado como seu assessor, para o que eles chamavam de Promoção Humana. [...] Na verdade, o que comecei a realizar era um trabalho de educação popular, que tanto podia se dar a nível da pósalfabetização como da alfabetização também (Idem, p. 88). ${ }^{8}$

É importante descrever o contexto político-social do Chile no momento em que Paulo Freire chegou lá, pois este também se mostra como fator determinante de sua postura frente à educação e os movimentos populares. Neste cenário ele comenta:

\footnotetext{
${ }^{8} \mathrm{Si}$ bien recuerdo, llegamos a Arica un viernes, y el segundo día fui llevado por Santiago de Mello y por el Strauss al gabinete de Jacques Chonchol, del Instituto de Desarrollo Agropecuario. A pesar de mi dificultad en entender el castellano de Jacques, tuvimos una charla muy cordial, y salí de su gabinete contratado como su asesor, para lo que ellos llamaban allá de Promoción Humana. [...] En el fondo, lo que empecé a hacer era un trabajo de educación popular, que tanto podía darse al nivel de la post-alfabetización como de la alfabetización también (Idem, p. 88).
} 
Cabe lembrar que, quando cheguei ao Chile, havia uma verdadeira euforia da democracia cristã no poder; havia uma verdadeira conviç̧ão em grande parte do povo em torno do êxito do que se considerava a terceira via para toda América Latina. Enfim, foi tudo o que levou a juventude cristã a ir renunciando o discurso democrata cristão e a se radicalizar, para o partido socialista, marxista e para o partido comunista. Ou criando novos grupos revolucionários (Idem, p. 85). ${ }^{9}$

Entre estes novos grupos, destaca-se o Movimento Independente Revolucionário MIR que estava composto, como ele afirma, de uma juventude que sempre estava à esquerda de qualquer coisa, mas sempre com lucidez. Havia também o Movimento de Ação Popular Unitária - MAPU e a Esquerda Cristã, ambos compostos por dissidentes da democracia cristã.

Quanto à influência de suas ideias em meio ao novo governo da democracia cristã que se estabelecia no Chile, chegou aos grupos que se mostravam cada vez mais radicais por perceber que havia traços significativos de uma burguesia modernista na democracia cristã, Paulo Freire afirmou que esta radicalização que se desencadeou no país proveniente principalmente da jovem democracia cristã, com quem trabalhava diretamente, não se deu por sua influência, mas que todos os grupos que se formaram neste período de alguma forma aproveitaram, cada um a sua maneira, algumas de minhas propostas (Idem, p. 86).

\section{Chile e seu significado para a construção de seu pensamento educativo}

Em última instância, minha estadia no Instituto de Desenvolvimento Agropecuário, o Ministério da Educação, a Corporação da Reforma Agrária, minha convivência com suas equipes técnicas, através de quem me foi possível ter uma rica experiência em quase todo o país, inúmeras comunidades camponesas, de entrevistar a seus líderes; a própria oportunidade de ter vivido a atmosfera histórica da época, tudo isso me esclarecia dúvidas que trazia para o êxito, aprofundava hipóteses, me assegurava posições. Foi vivendo a intensidade da experiência da sociedade chilena, da minha experiência naquela experiência, que me fazia repensar sempre a experiência brasileira, cuja memória viva eu levava comigo para o exílio, que escrevi em Pedagogia do oprimido entre 1967 e 1968 (ibidem, p. 53). ${ }^{10}$

\footnotetext{
${ }^{9}$ Es bueno recordar que cuando llegué a Chile había una verdadera euforia con la llegada de la democracia cristiana al poder; había una verdadera convicción en gran parte del pueblo en torno al éxito de lo que se consideraba la tercera vía para toda América Latina. En fin, fue todo lo que llevó a la juventud demócrata cristiana a ir renunciando al discurso demócrata cristiano y a radicalizarse, para el partido socialista, marxista, para el partido comunista. O creando nuevos grupos revolucionarios (Idem, p. 85).

${ }^{10}$ En última instancia, mi estancia en el Instituto de Desarrollo Agropecuario, el Ministerio de Educación, la Corporación de la Reforma Agraria, mi convivencia con sus equipos técnicos, a través de quienes me fue posible tener rica experiencia en casi todo el país, un sin número de comunidades campesinas, de entrevistar a sus líderes; la propia oportunidad de haber vivido la atmósfera histórica de la época, todo eso me explicaba dudas que traía para el exilio, profundizaba hipótesis, me aseguraba posiciones. Fue viviendo la intensidad de la experiencia de la sociedad chilena, de mi experiencia en aquella experiencia, que me hacía repensar siempre la experiencia brasileña, cuya memoria viva me traía conmigo para el exilio, que escribí la Pedagogía del oprimido entre 1967 y 1968 (ibidem, p. 53).
} 
A obra Pedagogia do Oprimido ${ }^{11}$ que estava sendo escrita quando o autor teve seu primeiro contato com a cultura chilena, foi concluída quando ele ainda estava exilado, mas antes de ser publicada, foi no exílio que Paulo Freire escreveu outras obras, destacando-se seu primeiro livro, intitulado Educação e atualidade brasileira, tese elaborada para o concurso em para uma vaga de professor na Universidade de Pernambuco e depois escreveu "Educação como prática de liberdade". Foi também no Chile que Paulo Freire revisou os escritos originais da tese que havia ficado no Brasil no momento de sua partida imediata. Depois da revisão que realizou de todo o texto, aproveitou a companhia de outros intelectuais que estavam lá para imprimir um parecer crítico, destacam-se Álvaro Vieira Pinto e Francisco Weffort, este último, inclusive, é quem elabora a introdução desta obra.

Aquele foi um período de intensa produtividade, pois além de assessorar diversas ações e projetos no Chile, se concentrou na escrita, como ele mesmo destacou: como escrevi neste período! Cheguei até a fazer a conta, escrevi 1600 páginas em um ano e meio, manuscritas. (Idem, 94). Publicou também outra obra, Ação cultural para a liberdade, que é fruto de experiência somada a outro trabalho de assessoria que desenvolveu no Chile, esta vez na Corporificação da Reforma Agrária-CORA. Seu registro foi assim descrito:

Para todo o encontro a que eu ia, escrevia um texto. Por exemplo, durante o tempo em que trabalhei no ICIRA, ofereci assessoria técnica às equipes que trabalhavam na Corporificação da Reforma Agrária (CORA). Foi quando escrevi todos os textos que estão na Ação cultural para a liberdade. Enfim, quase todos os meus textos foram tão vivenciados que, de vez em quando, me ponho a recorrer a um e outro e, revisando aqui e lá, faço uma espécie de viagem ao passado, entende? Revivi todos os momentos (Idem, p. 96). ${ }^{12}$

De fato, essas expressões revelam como Paulo Freire foi absorvido por toda a influência cultural recebida e alterada na experiência de exílio. A partir disso, para a

${ }^{11}$ Como todos os leitores de Paulo Freire sabem, a obra Pedagogia do Oprimido foi publicada pela primeira vez em Inglês, embora o livro já se encontre em sua 50a edição em Português. Esta nota tem a finalidade de informar que em 2013 no Cinquentenário de Freire em Angicos, aparecer a publicação dos originais da Pedagogia do Oprimido é fac-simile. Estes originais estiveram todo o tempo sob a custódia de Jacques Choncol, ministro da Agricultura do Governo de Salvador Allende, no Chile (1970-1973), amigo e chefe de Paulo Freire no Instituto de Desenvolvimento Agropecuário (INDAP), no período de seu exílio no Chile. Em 2013, os originais foram entregues ao governo brasileiro conforme as próprias palavras de Chonchol “"“Algumas vezes cheguei a pensar que não fazia sentido em ficar com ele. Pensei em doar o manuscrito à UNESCO. Ainda bem que não fiz, porque me parecer mais adequado que ele fique no Brasil, na terra de Paulo Freire, à disposição da humanidade" (Entrevista com Jacques Chanchol - publicado em Pedagogia do Oprimido - O manuscrito, p. 32). A obra foi publicada pelo Instituto Paulo Freire e a Universidade Nueve de Julio, 2018.

${ }^{12}$ Para todo encuentro a que iba, escribía un texto. Por ejemplo, durante el tiempo en que trabajé en el ICIRA, ofrecí asesoría técnica a los equipos que trabajaban en la Corporación de la Reforma Agraria (CORA). Fue cuando escribí todos los textos que están en la Acción cultural para la libertad. En fin, casi todos mis textos fueron tan vivenciados que, de vez en cuando, me pongo a recoger uno u otro y, revisando aquí y allá, hago una especie de viaje al ayer, entiende? Revive todos los momentos (Idem, p. 96). 
elaboração de sua obra de maior volume, a Pedagogia do Oprimido, não levou muito tempo, pois, como afirma "eu iniciei, e logo tomei um certo gosto pela escrita. Foi a partir disso que escrevi e comecei a Pedagogia do Oprimido".

Nos últimos dois anos de exílio no Chile, Paulo atou no Instituto de Capacitação e Pesquisa em Reforma Agrária e aponta este período como um dos momentos mais produtivos de sua experiência no exílio, pois já havia adquirido amplos saberes da realidade local que a experiência nos outros empreendimentos em que se envolveu o proporcionou.

Paulo reconhece a influência de intelectuais latino-americanos em sua teorização educacional ${ }^{13}$. Destacou como contribuições destes saberes adquiridos a participação ativa em discussões e debates no período do exílio. Nos anos 1992, reconhece a influência de seus amigos em sua obra, quando afirma que "com eles debati em vários momentos que a Pedagogia do Oprimido ainda estava em processo de escrita. Eu não posso negar o bem que a amizade de ambos me fez e a contribuição inteligente que eles me proporcionaram" (1992: $53)$.

\section{Singularidade e Universalidade do Pensamento de Freire (AL, AN, África, Europa)}

O pensamento do pedagogo e filósofo da educação Paulo Freire, nos leva a considerar seu trabalho a partir de duas direções: uma que se refere à singularidade de seu trabalho no umbral das transformações de uma sociedade fechada que tentava se abrir nos planos político, social e social econômico e outro, que se refere à universalidade de seu pensamento, tendo em vista seu alcance em outros países. É no Brasil dos anos 50/60 que Paulo, mergulhado em muitas influências intelectuais e políticas, enfoca na prática pedagógica a respeito da qual posteriormente elaboraria toda sua teoria de educação.

A singularidade do solo em que o pedagogo realizou seu trabalho pode ser chamada de singularidade ampliada, pois se tratava da experiência de opressão dos cidadãos do terceiro mundo. Ela é singular porque seu projeto se propõe a reintegrar ao indivíduo no mundo como um ser de relações e, por tanto, possibilita a retomada de sua natureza como homo politicus.

Outra direção a que nos referimos aponta a universalidade de suas ideias e práticas. É claro que não estamos afirmando que as ideias de Freire foram universalmente aceitas por onde quer que tenham chegado. Seu pensamento, e especialmente sua prática pedagógica, têm sofrido inúmeras críticas, sobre este ponto falaremos adiante.

\footnotetext{
${ }^{13}$ Faz referência a dois especificamente, a chilena Marcela Gajardo e o brasileiro José Luiz Fiori que em 1992, atuavam como pesquisadores e professores da Facultade Latino-Americana de Ciências Sociais.
} 
Quando falamos em universalidade, nos referimos à repercussão que suas ideias tiveram nos lugares/continentes por onde passou. O que estou chamando de singularidade e universalidade do pensamento de Freire não deve ser lido apenas na repercussão da ação prática de seu método de alfabetização no Brasil e no mundo, mas em sua proposta pedagógica de uma educação libertadora e conscientizadora, que pode ser universalizada em qualquer espaço em que homens e mulheres se encontrem em uma situação de aculturação opressora e desumanizadora. Especialmente neste momento em que a globalização e o neoliberalismo puderam internacionalizar os mercados, internacionalizando, consequentemente, a miséria e a opressão dos excluídos, a proposta por uma educação problematizadora e conscientizadora de Freire se destina não só ao Brasil e ao terceiro mundo, mas sua urgência pode ser percebida e reclamada inclusive nos paraísos do capital neoliberal.

O professor José Eustáquio Romão (diretor do Instituo Paulo Freire/Brasil) nos conta, em uma entrevista à BBC - "Uma vez, eu estava no deserto de Góbi, na Mongólia, com o povo nómade, em missão. Em uma tenda, vi aos criadores de cabra sendo alfabetizados por dois professores. Eu não entendia nada do que eles falavam, mas um nome soava um tanto famíliar. Era Paulo Freire. "Eles estavam com o último capítulo da Pedagogia do Oprimido nas mãos, traduzido ao chinês, que trata justamente do método de alfabetização".

\section{A Pedagogia Crítica - a universalidade de seu pensamento}

Como destaca Giroux; "A pedagogia crítica, para Freire, significava imaginar a alfabetização não só como domínio de habilidades específicas, mas também como um modo de intervenção, uma maneira de aprender e ler a palavra como base para intervir no mundo". O pensamento crítico não se reduz a uma lição objetiva na realização de uma prova ou na tarefa de memorizar os chamados feitos, descontextualizados e não relacionado às condições atuais. Pelo contrário, tratava-se de oferecer uma maneira de pensar além da aparente naturalidade ou inevitabilidade do estado atual das coisas, desafiando suposições validadas pelo "sentido comum", subindo além dos limites imediatos das experiências, entrando em um diálogo com a história e imaginando um futuro que não apenas reproduza o presente.

Assim, a pedagogia crítica insiste que uma das tarefas fundamentais dos educadores é certificar-se de que o futuro aponta o caminho para um mundo mais socialmente justo, um mundo no qual a crítica e a possibilidade em conjunção com os valores da razão, da liberdade e igualdade - função para alterar os motivos em que a vida é vivida. Ainda que renegue uma noção de alfabetização como a transmissão de fatos ou habilidades relacionadas às últimas 
tendências do mercado, a pedagogia crítica dificilmente é uma receita para a doutrina política, como insistem os defensores de sua padronização. Oferece aos alunos novas maneiras de pensar e agir de forma criativa e independente, deixando claro qual é a tarefa do educador.

A pedagogia crítica insiste que a educação não pode ser neutra. A educação é sempre um ato administrativo em sua intenção de capacitar os alunos a entender o mundo em sua profundidade e seu papel na história. Além disso, é inevitável uma tentativa deliberada de influenciar em como e que conhecimentos, valores, desejos e identidade se produzem dentro de conjuntos particulares de relações de classes e relações sociais. Para Freire, a pedagogia pressupõe sempre alguma noção de futuro mais igualitário e justo; e, como tal, deve sempre funcionar em parte como uma provocação que leva aos estudantes para além do mundo que eles conhecem, a fim de expandir o leque de possibilidades humanas e valores democráticos.

É para esses elementos, entre muitos outros, que sua concepção pedagógica chamada pedagogia crítica deslocou seu pensamento do local para o global. As experiências de opressão, de deseducação, de desumanização são experimentadas por todas as sociedades, desde as mais justas às mais injustas. As categorias epistemológicas de Freire seguem hoje em dia, o que não devemos fazer é repetir sua pedagogia como receita, mas ao contrário, como sempre nos incentivou - fazer novas pedagogias de acordo com cada contexto, como expõe muito bem Michael Apple. Parto de Freire encharcado em meu próprio contexto. Certamente chegaremos ao mesmo lugar. Uma educação crítica e libertadora de nossa humanidade desumanizadora.

\section{Teses e críticas ao pensamento de Paulo Freire}

Penso que para começar a análise da crítica do pensamento freireano, não se deve apoiar em uma cronologia de seus escritos (com os riscos de linearidade) e as mudanças que foram sofrendo ao longo de sua trajetória teórico-acadêmica. Poderíamos falar, como é o costume em história de trajetórias intelectuais, de pelo menos três Freire, ou, melhor dizendo, três momentos históricos do discurso freireano (SCOCUGLIA, 1999): O primeiro corresponde a seus escritos entre os anos 1959 até 1970, nos quais se destacam os escritos "Educação e atualidade brasileira"; "Educação como prática de liberdade e conscientização", ambos elaborados a partir de uma cosmovisão liberal e desenvolvimentista sobre a construção de uma nação moderna, e orientado por uma concepção do humanismo filosófico-católico da crença no Ser.

Nesse sentido, tem-se uma visão da sociedade brasileira de passagem (em trânsito) em busca da desejada modernização. Um projeto envolvido em luta política entre dois blocos da 
burguesia: o comercial-agrário e o urbano-industrial, frações hegemônicas das elites dirigentes entre os anos 1950-1960.

As primeiras críticas, em especial a da intelectualidade brasileira e latino-americana, em geral, estão centradas neste período da trajetória inicial de Freire e nos primeiros textos. "Os críticos elogiarão a análise do seu pensamento político e pedagógico como idealista, subjetivista e reformista" (Paiva, 1980; Rojo, 1948). O próprio Paulo reconhece algumas fragilidades de sua análise da realidade, mas a refuta (1984) afirmando que os críticos não leram o desenvolvimento de seu pensamento. Fixaram-se primeiro em Freire.

Estas são as críticas que venho recebendo, sobretudo na América Latina. Parece-me, no entanto, que quem me classifica desta forma, baseando-se em momentos ingênuos de alguns dos meus trabalhos, criticados hoje também por mim, deveriam ser obrigados a seguir os passos que dei. Na verdade, em meus primeiros estudos, ao lado da ingenuidade há também posições críticas. Ademais, não adoto a ilusão ingênua e pouco humilde de alcançar a criticidade absoluta (FREIRE, 1984, p. 24). ${ }^{14}$

O segundo, que se pode dizer, historicamente determinante do pensamento freireano, coincide com seu período de exílio, durante toda a década de 70 e início dos anos 80 do século passado. Nesse se encontra seu trabalho na Europa, África e América Central.

Aqui a elaboração de suas ideias destacadas pela experiência vivenciada no Chile, sua participação no movimento popular e os grandes debates e ações sobre a reforma agrária no país. Segundo nossa interpretação, destaca-se um pensamento estruturado em duas abordagens teóricas - a primeira de natureza pedagógica que aparece na Pedagogia do Oprimido, e a segunda, de natureza político-pedagógica, mais específica que aparece nas reflexões do livro Ação cultural para a liberdade.

Acredito que as críticas que aparecem fruto dos textos anteriores não levam a pensar que depois da autocrítica e as contribuições da crítica, há um deslocamento na obra freireana. A proximidade com as categorias marxista-gramscianas vão contribuir e orientar sua obra. A Pedagogia do Oprimido inaugura o segundo Freire que se coloca em diálogo com Luckás, Gramsci, Marx, Sartre. Estas novas contribuições que vão determinando sua ruptura com as posições liberais, nacionalistas, populistas e do humanismo católico do primeiro Freire.

Com o tempo, é preciso chamar a atenção para que não esqueçamos que esse período não nos permite afirmar um Freire Marxista, como afirmei em muitas ocasiões, que não foram

${ }^{14}$ Esas son críticas que se me vienen haciendo, sobre todo en América Latina. Me parece, sin embargo, que quienes me califican así, basandose en momentos ingenuos de algunos trabajos mios, criticados hoy por mi también, deberían obligarse a seguir los pasos que he dado. En realidad, en mis primeros estudios, al lado de ingenuidades hay también posiciones críticas. Por lo demás, no abrigo la ilusión ingenua y poco humilde de alcanzar la criticidad absoluta (FREIRE, 1984, p. 24). 
as categorias marxistas que o levaram à educação popular, pelo contrário, as experiências com a educação popular o levaram à busca de abordagens e instrumentos teóricos para compreender melhor as lutas e experiências populares.

Para chegar ao terceiro Freire, precisamos olhar para a virada epistemológica que ele faz do conceito de "conscientização". De uma maneira mais próxima, essa contribuição já foi colocada em seu pensamento desde os primeiros passos guiados pelos Isebianos ${ }^{15}$. Qual seja: a "consciência" é gerada por meio de etapas crescentes que vão desde a concepção mais ingênua, passando pela transitiva e chegando à consciência crítica. Com estas categorias, Freire vai se aproximando mais da consciência de classe lukacsiana (LUKÁCS, $2003^{16}$ ) que poderia chegar pela "mediação dialética" na qual a consciência de classe surge de uma "interação" entre a consciência espontânea da classe trabalhadora e o trabalho educativo do Partido (ZIZEK, 2003).

Com efeito, a categoria "luta de classe" o trouxe muitos inconvenientes para sua compreensão de consciência (TORRES, 1979), uma vez que Freire não aceitava a luta de classe como o motor da História. Ainda assim, de acordo com Scocuglia (1999), com o qual concordamos, essa abordagem da consciência e da luta de classes constitui um salto importante em sua análise social da educação.

\begin{abstract}
Nesse sentido, com a política sendo"substantiva" e a pedagogia "adjetiva", a concepção inicial de uma educação para a mudança "interna" do homem, via conscientização de âmbito psico-pedagógica(sic) e que implicaria a transformação de toda a sociedade. Com efeito, nos seus últimos escritos, Freire concentrou-se na "criação histórica" - com os trabalhadores, estudantes, professores, em seus sindicatos, associações, comunidades, escolas, de uma outra educação que só seria possível na mudança profunda da sociedade, da política(gem), da ética, do cotidiano dos indivíduos e dos grupos sociais. Uma educação de resistência, que não aceita a exploração continua da dos oprimidos ou outros pretextos escusos. Uma educação "para a autonomia e para a capacidade de dirigir" ou, como defendia Gramsci, para a "contra hegemonia dos subalternos" (p. 35).
\end{abstract}

15 Isebianos se refere aos intelectuais que estiveram na linha de frente do ISEB (Instituto Superior de Estudos Brasileiros) - órgão governamental do Ministério da Educação e Cultura, criado por um decreto número 37.608 de 14 de julho de 1955, com objetivos de estudar a realidade brasileira da metade do século XX, com a finalidade de promover estudos e formulação de propostas para o desenvolvimento nacional. $\mathrm{O}$ Instituto foi $\mathrm{O}$ mentor da elaboração do projeto nacional - desenvolvimentista no Brasil. Seus principais intelectuais e fundadores foram Helio Juaguaribe, Guerreiro Ramos, Cândido Mendes, Álvaro Vieira Pinto e Nelson Werneck Sodré.

${ }^{16}$ Lukács, em seus estudos sobre a consciência de classe, ainda que negue uma tipologia histórica e sistemática de possíveis níveis de consciência, indica que ela vai se estabelecendo em níveis (LUKÁCS, G, 2003, p. 147). 
Uma das críticas mais severas a Freire se refere exatamente à questão da universalidade de seu pensamento (método). Linda Harasim ${ }^{17}$, em sua tese, aponta que a teoria e a prática de Freire não foram capazes de realizar o trabalho de alfabetização consciente que ele e sua equipe propuseram em África, em Guiné Bissau. A autora indica como fator principal deste fracasso a imposição de uma visão ocidental em uma sociedade africana. Possivelmente, segundo a pesquisadora, pensava Freire que seu método tinha um valor universal e poderia ser apropriado a qualquer sociedade do terceiro mundo ${ }^{18}$. A autora acusa a Freire de uma visão romântica de educação e política. Afirma que a contradição fundamental de seu trabalho em África reside no fato de que o conceito de Freire de política foi enraizado nas noções morais e filosóficas e não contém implícito um plano de ação.

Em geral, as críticas estão direcionadas ao "método", pois os experimentos de sua pedagogia forma mais no campo da prática de alfabetização de adultos vivenciados nas campanhas de alfabetização que ocorram em África e América Latina que outras abordagens de natureza teórica inscritas no método.

Segundo Kubota (1996), o método de Freire pressupunha um contexto já envolvido, peneirado pelo mercado capitalista, no qual a opressão é a realidade social incorporada na condição material. É uma sociedade de classes, uma certa relação de opressão seria experienciada pelo trabalhador, pelo camponês, etc, e junto com ele uma consciência e interesse na alfabetização. No Brasil, havia uma economia de mercado que o motivou à aprendizagem da leitura e da escrita, e também ao político, já que só os alfabetizados podiam votar. No entanto, os críticos apontam que havia uma grande contradição entre os pressupostos implícitos nas estratégias freireanas e nas condições socioeconômicas e históricas de outros países nos quais tem desenvolvido seu método (SAENZ, 1981; LA BELLE, 1987; FREYHOLD, 1979; HARASIM, 1983).

No caso da Nicarágua, as pessoas podem ter experiência similar com os trabalhadores brasileiros e camponeses sem terra. Em África, no entanto, as experiências foram diferentes das da América Latina. Por exemplo, em Guiné-Bissau não havia uma só língua - uma linguagem comum e quase não havia desenvolvimento de relações de mercado no modo capitalista mais avançado. No setor rural, os camponeses estavam debilmente relacionados com as relações de mercado. Vivendo somente de agricultura de subsistência, a experiência

\footnotetext{
${ }^{17}$ Harasim no trabalho de tese de doutorado em 1983, defendida na University of Toronto, com o título "Literacy and national reconstruction in Guinea Bissau: a critique of the Freirean literacy campaign" faz a primeira crítica sistemática e acadêmica do pensamento de Paulo Freire.

${ }^{18}$ Aqui usamos a expressão ou o conceito-termo pelo qual organizações internacionais designam países como subdesenvolvidos no século XX.
} 
generalizada de opressão social no camponês não estava diretamente submersa na cultura do opressor. Nesta situação, a alfabetização crítica pode ter falhado em aumentar a consciência crítica entre analfabetos.

Nestes termos que apresentamos, a crítica está mais acentuada no método e, portanto é necessário avançar no exame do pensamento freireano. Conforme menciona Kobota (1996, p. 81):

No âmbito da reflexão sobre as práticas de letramento em diferentes países, reconhecemos que o processo de implementação da teoria de Freire apresenta uma variedade de dificuldades que dependem de muitos fatores, além da orientação política, o contexto socioeconômico, assim como os aspectos humanos e materiais. Na prática o método de diálogo também se transforma em uma espécie de questionário oral, em vez de uma discussão estimulante que Freire pode inspirar e desafiar a aqueles que estão envolvidos em atividades de alfabetização, mas não oferecer uma solução (Miller, 1982). E, certamente, sabemos que não existem fórmulas mágicas. O importante é desafiar as pessoas que precisam aprendem os demais e juntos criarmos nosso próprio futuro para uma prática autêntica ${ }^{19}$.

De nossa parte, somos freireanos que mantêm um de seus conselhos, ou seja, esquecendo-se de construir capelas e encapsular seu pensamento, mas avançando nos fundamentos da pedagogia crítica sem dogmatizar o conhecimento dos "pais" fundadores. Portanto, como já mencionei em outras críticas ${ }^{20}$ ao pensamento de Freire, em especial ao uso que às vezes se faz dele. Deixei de usar conceitos de Freire por ter encontrado outros mais adequados a meus fenômenos de pesquisa. Ler, entender e criticar é um movimento necessário e respeitável. No entanto, é inadmissível que a mediocridade intelectual de alguns baseados em "slogans" seja levada a sério. Aqueles que replicam discursos de milícias digitais que jamais leram uma orelha do livro do autor, que "politizam e moralizam" sem nenhum critério, não merecem consideração. Infelizmente, em meu país foram pessoas deste tipo que tentaram retirar o título de Patrono da Educação Brasileira de Paulo Freire (Projeto de Lei de um parlamentar brasileiro).

\footnotetext{
${ }^{19}$ Reflecting on the literacy practices in four different countries, we soon recognize that the process of practical implementation of Freire"s theory present a variety of difficulties depending on many factors apart from political orientation, such as social-economic context as well as human and material resources. In practices, the dialogue method also turns into $\mathrm{s}$ kind of oral questionnaire rather tham a stimulating discussion. Freire can inspire and challenge those who are involved in literacy activities, but he cannot give solution (Miller 1982) And of course, we know there are no magic formulas. The important thing is to challenge people who must learn from others experience and create their own future by authentic praxis (KOBOTA, 1996, p. 81).

${ }^{20}$ LIMA-JARDILINO, José Rubens. Paulo Freire, filósofo, pedagogo e cientista social: singularidade e a universalidade do seupensamento. Revista Historia de la Educación Latinoamericana, n. 10, Tunja, p. 40-56. LIMA-JARDILINO, José Rubens. Paulo Freire: apuntes biobliográficos. Bogotá: Editorial Magistério, 2009.
} 
Uma das críticas que apontei se refere ao chamado "romanticismo de Freire" com seu projeto de educação em uma concepção salvadora do homem. Uma leitura teológica dos conceitos de Paulo Freire se tornou, por toda América Latina, muito em voga nos anos 80. Possivelmente, pela similitude temática com a linguagem da Igreja latino-americana, após o Concilio Vaticano II e as conferências episcopais de Puebla e Medelín. Por outro lado, na Igreja Oficial e conservadora, também proliferaram críticas duríssimas às ideais e conceitos de opressão/libertação.

Para falar da importância e da influência do religioso na obra do autor, reproduzimos suas próprias palavras em uma correspondência a um jovem teólogo: “Ainda que eu não seja teólogo, mas um "enfeitiçado" pela teologia que marcou muitos aspectos de minha pedagogia, às vezes, a impressão de que o terceiro mundo(sic) pode, portanto, se transformar em uma fonte inspiradora do ressurgimento teológico".

Para compreender os temas básicos que subjazem ao conteúdo filosófico da pedagogia de Freire, é importante reconhecer a influência do existencialismo, da fenomenologia, do marxismo e do cristianismo. Seu pensamento foi formado por tensões de teses filosóficas junto com o humanismo clássico (KUBOTA, 1996) ${ }^{21}$.

De modo muito mais amplo, podemos afirmar que a questão religiosa acompanha a obra de Paulo desde os primeiros momentos de sua formação intelectual. É possível perceber em seus primeiros escritos que a influência sobressalente do humanismo cristão, autores como Tristán de Athayde, Jacques Maritain, Emmanuel Mounier, entre outros. Em uma perspectiva cronológica, podemos perceber as orientações cristãs religiosas pelas quais Freire transita. Poderíamos dizer que nos primeiros anos, as ideias religiosas de seu trabalho foram marcadas pela corrente humanista e pelo existencialismo. Sua obra denota claramente uma reação às visões de mundo que minimizavam o potencial de ser e reduziam o homem a uma coisa à mercê das entidades superiores, especialmente o estado e o mercado em que o homem perde sua própria consciência.

As correntes do humanismo buscam reorientar as energias do homem para devolver a ele o lugar de protagonista da história. De onde podemos perceber seu direcionamento até uma via mais existencialista, em que se encaminha para afirmar que o ser definitivo não existe, pois ele é existência e, portanto, é no tempo e não fora dele que o homem se define como um "ser/sendo". Entendemos isso como um humanismo que se apresenta em toda a

21 To understand the basic themes underlying philosophical content of Freire's Pedagogy it is important recognize the influence of the Existentialism, Phenomenology, Marxism end Christianity. His thought was shaped by thesis philosophical strains along with his classical humanism (KUBOTA, 1996, p. 70). 
obra de Freire: o valor do homem e a busca por sua libertação. Com isso, Paulo, consciente da realidade concreta em que vive o home, chega até Marx, ainda sem ter jamais se tornado um marxista. No exílio, Paulo se dncontra frente à realidade mais dura dos poderes políticos de castração na América Latina, no qual pode perceber a importância das ferramentas de análise do pensamento de Karl Marx para olhar para a realidade, por ter examinado as relações econômicas e os modos de produção capitalistas. Nessa situação, Freire percebe a atualidade desses instrumentos em seu trabalho.

A partir deste encontro, que o reorientou no sentido da filosofia da práxis, Freire retrata a relação de opressor/oprimido que tece as relações humanas por meio de jogos de poder alienantes, estabelecendo claramente a situação de dominação entre os homens. É essa visão do homem que ele tem e a busca pelo 'novo homem' que ele eleva a libertação determina uma visão de mundo religiosa da obra de Paulo, fundamentalmente baseada nos imperativos do evangelho: Esperança, amor, denúncia/anúncio [profetismo], utopia da libertação. Como afirma um de seus intérpretes: "em Freire, o teológico sub-existe permanentemente como fonte de reflexão e ação, como compromisso e práxis".

Portanto, três antagonismos se constituíram como conceitos fortes na obra do autor, são o que chamamos chaves de interpretação da influência religiosa na obra de Paulo Freire: Opressão/Libertação; Esperança/Consciência; Denúncia/Anúncio e a melhor tradição do profetismo bíblico. Para muitos de seus intérpretes, estes pares antagônicos são uma forte expressão da dialética no pensamento freireano.

No entanto, por meio deles, poderemos saltar da antropologia para a pedagogia e desta para a teologização da obra de Freire. Certamente ele não é teólogo, o que fazemos é um esforço para compreendê-lo desta forma, uma vez que foi também "mergulhado" nas águas do cristianismo, na forte cultura cristã no nordeste brasileiro. Pode-se concluir que Freire nunca deixou o humanismo cristão.

\section{Conclusão}

\section{Depois de Freire: leitura freireana frente a uma América Latina neocolonizada}

Neste momento político que sofremos perdas consideráveis na América Latina, com um avassalador controle de mercado e capital no continente, é hora de refletir muito mais sobre a obra de Freire e seu especial valor para a compreensão e atuação no mundo em que vivemos. Não repetir Freire, mas fazer novas pedagogias, propor novas epistemologias da relação SUL-SUL, romper e resistir ao neocolonialismo do pensamento que nos impõe a 
antiga metrópole. Estamos em um movimento, como indicam Souza Santos (2010) e Mignolo (2003), em busca de uma (de)colonização, não para rejeitar os saberes que ganhamos com o norte, mas para afirmar que existem outros modos de pensar e viver, há outras formas de conceber o saber, outras epistemologias. A juventude nos deu provas concretas disso, por exemplo, como o movimento estudantil que se espalhou por toda a América Latina para o ressurgimento do movimento foi ensaiado no Chile, lembrando o centenário do Movimento Estudantil de Córdoba.

Por isso, para refletir sobre este processo podemos finalizar este ensaio com algumas perguntas: quais são os projetos de descolonização? Que projetos temos hoje em nossos países que indicam uma luta contra o colonialismo do saber e do poder? E que indicam uma resistência - uma atitude e ação de descolonização?

É possível que a concepção de educação que pode acolher as ideias do pensamento de Freire hoje, seja uma pedagogia da (de)colonização e uma aproximação das epistemologias do sul, com a finalidade de mudar o pensamento hegemônico estruturado na racionalidade técnica produzida pela modernidade e pelo capitalismo. O desafio de uma nova leitura de Freire agora como um clássico ${ }^{22}$, é construir um pensamento pedagógico para além do capital, como nos aconselha Mészáros (2008).

\section{REFERÊNCIAS}

APPLE, M. Expanding the dynamics of power: Freire and the politics of race in education Revista eCurriculum, São Paulo, v. 14, n. 1, p. 277-295, jan./mar. 2016.

CALVINO, I. Por que ler os clássicos. São Paulo: Companhia das Letras, 1993.

COLLINS, D. Paulo Freire: his life, works and thought. New York: Paulist Press,1997.

FREIRE, P. Pedagogía de la esperanza: un reencuentro con la pedagogía del oprimido. 5. ed. Río de Janeiro: Paz y Tierra, 1992.

FREIRE. P. Acción cultural para la libertad. Buenos Aires: Terra Nueva, 1975.

FREYHOLD, M. Some observation on adult education in Tanzania. In: HIZEN, H.; HUNDSDÖRFER, V. H. (Eds.). The Tanzanian Experience: Education of Liberation and Development. Hamburg: Unesco Institute of Education, 1979.

${ }^{22}$ Aqui me refiro ao conceito de "Clássico", tratado por Ítalo Calvino (1993). Para Calvino, "Os clássicos são livros que exercem uma influência particular quando se impõem como inesquecíveis e também quando se ocultam nas dobras da memória, mimetizando-se como inconsciente coletivo ou individual". [...] "Um clássico é um livro que nunca terminou de dizer aquilo que tinha para dizer." E mais: "Os clássicos são aqueles livros que chegam até nós trazendo consigo as marcas das leituras que precederam a nossa e atrás de si os traços que deixaram na cultura ou nas culturas que atravessaram (ou mais simplesmente na linguagem ou nos costumes)." (...) "Um clássico é uma obra que provoca incessantemente uma nuvem de discursos críticos sobre si, mas continuamente as repele para longe." (p. 10-12) 
GIROUX, H. Critical pedagogy: Paulo Freire and the courage to be political. Revista e-Curriculum, São Paulo, v. 14, n. 1, p. 296-306, jan./mar, 2016.

HARASIM, L. M. Literacy and national reconstruction in Guinea Bissau: a critique of the Freirean literacy campaign. 1983. 437 f. Thesis (Ph.D.) - University of Toronto, 1983.

KUBOTA, K. Literacy campaigns and pedagogy of Paulo Freire: a comparative view on literacy campaigns in Brazil, Nicaragua, Tanzania and Guinea Bissau. Departmental Bulletin Paper, Kansai University, p. 70, 1996. Disponível em: https://kuir.jm.kansai-

u.ac.jp/dspace/bitstream/10112/1001/1/KU-1100-19960100-03.pdf. Acesso em: 2 jul. 2018.

La BELLE, T.J. From consciousness raising to popular education in Latin America and Caribbean. Comparative Education Review, v. 31, n. 2, p. 201-217, 1987.

LIMA-JARDIINO, J.R. Paulo Freire, filósofo, pedagogo e cientista social: singularidade e a universalidade do seu pensamento. Revista Historia de la Educación Latinoamericana, Tunja, n. 10, p. 40-56, 2008.

LIMA-JARDIINO, J.R. Paulo Freire: apuntes biobliográficos. Bogotá: Editorial Magistério, 2009.

LUCKÁCS, G. História e consciência de classe: Estudos sobre a dialética marxista. São Paulo:

Martins Fontes, 2003.

MÉSZÁROS, I. Educação para além do capital. 2. ed. São Paulo: Boitempo, 2008.

MIGNOLO, W. Histórias locais / Projetos globais: colonialidade, saberes subalternos e pensamento liminar. Belo Horizonte: Ed. UFMG, 2003

SCOCUGLIA, A. C. Origens e prospectivas do pensamento político-pedagógico de Paulo Freire.

Educação e Pesquisa, São Paulo, v. 25, n. 2, p. 25-37, jul./dez. 1999.

SOUSA-SANTOS, B; MENESES, M. P. [Orgs.] Epistemologias do Sul. São Paulo: Cortez Editora, 2010.

TORRES, C.A. Diálogo com Paulo Freire. São Paulo: Loyola, 1979.

ZIZEK, S. De História e Consciência de Classe a dialética dos esclarecimentos, e volta. Revista Lua Nova, n. 59, p. 159-175, 2003. Disponível em: www.scielo.br/pdf/ln/n59/a08n59.pd. Acesso em: mar. 2020.

\section{Como referenciar este artigo}

LIMA-JARDILINO, J.R; SOTO-ARANGO, D.E. Paulo Freire e a Pedagogia Crítica: seu legado para uma nova pedagogia do Sul. Revista Ibero-Americana de Estudos em Educação, Araraquara, v. 15, n. 3 , p. 1072-1093, jul./set. 2020. e-ISSN: 1982-5587. DOI: https://doi.org/10.21723/riaee.v15i3.12472

Submetido em: 21/04/2019

Revisões requeridas em: 10/07/2019

Aprovado em: 20/11/2019

Publicado em: 20/02/2020 